Teaching and Learning (2009) 5(1), 63-69

\title{
Differentiated Instruction: Planning for Success
}

\author{
RANDY HILL \\ Brock University \\ DON DWORET \\ Brock University
}

\begin{abstract}
The make-up of classrooms across Ontario is becoming increasingly inclusive in composition. Many classrooms now include students with exceptional needs In ability and disability and students from diverse backgrounds. This article presents an outline in planning for success in Ontario schools through Differentiated Instruction. The concepts of Universal Design for Learning (UDL) and Differentiated Instruction (DI) require teachers to transform their practices from program-based pedagogy to student-based pedagogy. Curriculum tells teachers what to teach while DI tells teachers how to teach. Teachers can differentiate classroom content, process and product. Planning for DI involves an approach which respects individuals and permits students to learn and demonstrate their learning in a manner most preferable to them. Student groupings based on the Ontario Ministry of Education, 2005 document Education for All are examined. Instructional techniques such as cooperative learning, project-based, problem-based and explicit instruction are discussed as sound pedagogy reflecting UDL and DI. The instructional approaches and strategies described are not new to teachers. What has changed is the emphasis on strategically responding to the individual needs of students in today's inclusive classrooms.
\end{abstract}

\section{Introduction}

Inclusiveness is not just a concept for teachers in Ontario classrooms today. It is a reality. Teachers are well aware that their classes are composed of students from many different cultural, socio-economic, religious, and ethnic backgrounds. One approach to effectively teaching in classes with such a diverse population is through Differentiated Instruction. This approach is formally discussed in the 2005 document entitled Education for All: The Report of the Expert Panel on Literacy and Numeracy Instruction for Students with Special Education Needs, Kindergarten to Grade 6 (MOE, 2005). The essence contained in this document reflects an 
emphasis on both Universal Design for Instruction (UDI) and Differentiated Instruction (DI). Universal Design for Instruction is "a technique to enhance learning of all students" (Turnbull et al., 2005, p. 92) in which a classroom welcomes students to a barrier-free learning environment where all students feel accepted. Differentiated Instruction principles ensure that instruction meets the educational need of the diverse population of students placed in Ontario classrooms. Together, these two related approaches suggest that our educational delivery system should reflect an approach where all students, regardless of ability, can be successful in the regular classroom environment. More recently, the Ministry of Ontario is suggesting that these approaches should be extended to grades 7-12, therefore the inclusion of Differentiated Instruction in our daily teaching practices is essential.

What is Differentiated Instruction?

Differentiated Instruction (DI) is "a process of teaching and learning that begins with the premise that not all students are alike" (Burggraf, 2004). Tomlinson (1999) adds that DI is a teacher's response to a learner's needs guided by general principles of differentiation such as respectful tasks, flexible grouping and on-going assessment. Based on the readiness, learning preferences and interest of the student, teachers who differentiate instruction vary their teaching strategies and adjust curriculum and presentation of material in order to give students multiple paths to the same goals or outcomes. Differentiated Instruction is a process of instruction which "requires teachers to transform their practices from a program-based pedagogy to a student-based pedagogy." Teachers consciously adapt pedagogical interventions to the needs of each student, acknowledging that each student differs in interests, learning profile, and level of functioning. (Education for All, 2005, p. 14)

How do teachers differentiate for instruction?

For teachers, the first step in integrating Differentiated Instruction into their own instructional practices is developing an understanding of and respect for the differences in 
intellectual ability, readiness to learn, learning styles and interest of the students in their class. Teachers create profiles of each student in their class early in the school year by documenting each student's educational and socio-cultural background (Education for All, 2005). This educational profile should include: identification of particular needs, literacy and numeracy levels of performance, and any types of learning supports teachers have used in the past which led to effective gains. A complete profile also includes a socio-affective component, which involves obtaining information from the students and their parents on items such as personal interests, hobbies, out-of-school activities and friendships. Based on this information, the teacher develops appropriate groupings for effective collaborative educational projects and makes decisions about assigning projects on topics in which the student has expressed a learning interest.

The next step is for teachers to differentiate instruction so that the readiness, interest, and learning profile of each student is taken into account. Tomlinson (2005) suggests that instruction can be differentiated by adjusting three components: content, process and product.

\section{Differentiating Content}

Recognition of the knowledge, skills, and attitudes that students possess allows teachers to target instruction to meet student learning needs. The student profile contributes to this recognition and understanding; however, determining the various levels of prior knowledge of a new topic or concept being introduced is essential to the planning process. Either through pretesting or curriculum achievement testing, teachers can determine the level of student understanding and allow those students who understand the material to move ahead past the initial teaching to an application stage, skipping the direct instruction others may require. This strategy is called compacting or accelerating the curriculum, possibly allowing those students to work independently. Alternately one may slow down the instruction breaking the concept or skill down into its component parts, teaching each piece in a logical sequence based on the method Task Analysis. The key to differentiation is that all students in the class, exceptional or not, can achieve with success based on appropriate activities in an environment planned and organized to meet everyone's needs. 
After determination of levels, the initial planning of lessons must ensure that needs of individuals are taken into consideration. Lessons should encourage the use of written, oral and visual (graphic) presentation of material, while assessment should permit students to reveal their understanding through oral response, written response or through the use of technology. During planning, teachers design lessons that provide for a variety of groupings to meet student needs, providing accommodated instruction/assessment activities where required, and challenging students at an appropriate level (through modifications), in light of their readiness, interests, and learning profiles (Ontario Ministry of Education, 2005).

In a differentiated class, the teacher provides instruction at the level students have reached in terms of the curriculum. The learning goals are adjusted to the abilities of each individual. Planning should include how students will be observed and evaluated in the learning situation to determine what the expectations should be, using a formative approach. Periodic overviews of skills are planned so decisions regarding adjustments to instruction will be made based on progress.

\section{Differentiating through Process}

Varying the learning activities or strategies in order to build success for all students is differentiating through process. With an understanding of each student's interests and preferred learning process, teachers develop and implement a range of classroom instructional and management strategies targeted to meeting those learning preferences. Teaching and instruction may include such strategies as graphic organizers, maps, diagrams and charts to enhance understanding.

As well, teachers employing differentiated instruction may include flexible grouping strategies which involve all students in the class working on the same topic and subject area, but at their level of understanding and achievement. This can be done individually through learning contracts or explicit instruction, in small groups through cooperative learning activities, projectbased learning, or problem-based learning, or as a whole group. George (2005) believed that "effectively differentiated classrooms are characterized by flexible grouping, through which students have opportunities to make meaning through interaction with a variety of peers" (p.188). To meet student learning needs, teachers are encouraged to use tiered lessons in which 
they assign different tasks to different students in the class, which allows students to engage in the learning successfully.

Cooperative learning emphasizes small group work and fosters positive interdependence and responsibility, which is an appropriate instructional model promoting differentiation as it allows students to support each other as they work together in searching for a solution. Additionally, students learn to share and understand one another, which will spread cooperation throughout the classroom. They learn to listen to one another, help and provide constructive criticism to one another in a courteous manner, and encourage others to express themselves (Hutchison, 2010).

Another approach outlined in Education for All (2005) is project-based instruction. Simply stated, students learn content related to student interest and create a project that demonstrates that learning. For example, a student may bring to science class a tadpole, and after group discussion, this may result in a great variety of projects - books, research, artwork, or posters related to the study of tadpoles. For teachers who are able to flexibly shift content direction based on that interest, this approach gives students' work meaning, and allows them to do work based on real issues and to experience an authentic task in a real-life context (Education for All, 2005).

A third approach is the problem-based approach. The classroom teacher chooses the task or problem for the students to solve. These tasks are realistic and can be solved through the acquisition of a new skill. Teachers create problem situations for very specific purposes, and allow others to arise in a less planned manner. In both cases, these investigations are carefully planned so that content and cognitive challenges are effectively provided for their students (MOE, 2005).

It is important to note that students with special needs often require an explicit instruction approach. Students' abilities to learn independently fall on a continuum, so teachers must provide students with a range of structured to unstructured learning opportunities. This will require incorporating teaching strategies that use overt thinking processes such as modeling, thinking aloud, verbalizing thought processes, sharing relevant personal learning experiences, and opportunities for students to practice their new learning.

Differentiating process also includes varying the complexity of each activity within the lesson presentation. This may include creating alternative ways for students to demonstrate 
knowledge and skills, such as using drama, movement, art and music, which allows students to express their accomplishments in a way they feel most comfortable. This allows each student to express him or herself to the fullest, which provides students with opportunities to organize or generate ideas throughout all areas of the curriculum.

\section{Differentiating for Product}

The accomplishment following the learning period, is described by Tomlinson (2004) as the product. When the product is differentiated, complexity is varied thereby allowing students to achieve mastery at their performance ability. Many students require accommodations or changes to tasks or instruction presentation to match learning needs. Students who are not at grade level may require curriculum modification or changes to the content of the learning expectations that are different from the age and/or grade placement of the student, including changes in the outcomes.

Accommodations provided may include special teaching and assessment strategies, human supports (such as a peer assistant or teaching assistant), and/or individual equipment that help the student learn and demonstrate learning. Accommodations can be provided to support learning needs in three situations: 1) during instruction, when adjustments are made through one or more teaching strategies; 2) within the environment, when changes or supports in the physical environment of the classroom are made; or 3) during assessment, adjustments are made in assessment activities or methods.

\section{Conclusion}

Differentiation is not something you do when the real lesson is finished. It is integral to ensuring each student has access to success with key content goals. By differentiating in process, product and content, students become more successful and more confident in their ability to achieve (Tomlinson, 2008).

Teachers already use many instructional techniques to enhance learning, such as cooperative learning, project-based or problem-based approaches to learning, and explicit instruction, which are compatible to the principles of Universal Design for Learning and Differentiated Learning (Ontario Ministry of Education, 2005). 
According to Rock, Gregg, Ellis, and Gable (2008), differentiating instruction is "not a passing fad" (p. 39). The instructional approaches and strategies described in this paper are not new to teachers - what has changed is the emphasis on strategically responding to the individual needs of students, resulting in today's inclusive classrooms. The time and effort spent is well worth it. All students, including those with disabilities, will benefit.

\section{References}

Burggraf, K. (2004). Differentiated instruction- laminated card. Arlington, VA: Council for Exceptional Children.

George, P. (2005). A rationale for differentiating instruction in the regular classroom. Theory into Practice, 44(3), 185-193.

Hutchison, N. (2010). Inclusion of exceptional learners in Canadian schools, $3^{\text {rd }}$ edition. Toronto: Pearson.

Ontario Ministry of Education (2005). Education for all: The Report of the expert panel on literacy and numeracy instructions for students with special education needs, Kindergarten to grade 6. Toronto: Queen's Printer for Ontario.

Tomlinson, C. A. (1999). The differentiated classroom: Responding to the needs of all learners. Alexandria, VA: Association for Supervision and Curriculum Development.

Tomlinson, C. A. (2008). The Goals of Differentiation. Educational Leadership November, 66(3), 26-28.

Turnball, R., Turnball, A., Shank, M., Smith, S., \& Leal, D. (2002). Exceptional lives: Special education in today's schools $3^{\text {rd }}$ edition. Columbus, $\mathrm{OH}$ : Merrill Prentice Hall. 